\title{
Child-to-parent violence: a study of socio-demographic causes in Ilorin Metropolis, Kwara State
}

DOI: http://doi.org/10.26758/9.1.16

Khalid Olatunji RAJI (1), Abdullateef RAJI (1), Deborah Shade ADEKEYE (1), Salihu Zakariya ABDULBAQI (1)

Department of Sociology, University of Ilorin, Nigeria

Address correspondence to: Raji Khalid Olatunji, Department of Sociology, University of Ilorin, Kwara State, Nigeria. Ph: +23-48-065-059-886; E-mail: rajikhalid90@gmail.com

\begin{abstract}
Objectives. Child-to-parent violence (CPV) is gradually attracting interest all over the world. Therefore, it is becoming a social problem. It has severe effects on the parents and the children. This study observed the socio-demographic causes of CPV in Ilorin metropolis of Kwara State. The study examines the association between the offender's religion and engagement in financial CPV. Also, there is an interest in the association between offender's age and involvement in psychological violence. Finally, there is an interest in the association between offender's gender and engagement in physical CPV.

Material and methods. In 2018, data were retrieved using a questionnaire with 258 copies found to be valid. The respondents were selected using multistage sampling, entailing cluster, simple random and purposive stages of sampling. In terms of gender, $57 \%$ of the respondents were male with $43 \%$ being female. In terms of age, $2 \%$ of the respondent were aged 18 and below; $25 \%$ aged $19-29 ; 33 \%$ aged $30-40,32 \%$ aged $41-51$, and $8 \%$ aged 52 and above.

Results. Offender's religion is not related to engagement in financial CPV, $\left[\mathrm{C}^{2}(1, \mathrm{~N}=258)=\right.$ $0.59, \mathrm{p}=0.44]$. Offender's age is related to involvement in psychological violence $\left[\mathrm{C}^{2}(1, \mathrm{~N}=258)\right.$ $=18.4, \mathrm{p}=0.001]$. Offender's gender is related to engagement in physical $\mathrm{CPV}\left[\mathrm{C}^{2}(1, \mathrm{~N}=258)=\right.$ $32.1, \mathrm{p}=0.001]$.

Conclusions. The study revealed that religion is not a significant factor influencing CPV. Age and gender on the other hand are significant factors. Grounded on this, the study recommends that non-governmental organizations could be established to educate the general public on the issue of CPV and its dangers.
\end{abstract}

Keywords: Child-to-parent violence (CPV), socio-demographic causes, Ilorin Metropolis.

\section{Introduction}

Violence has perhaps always been a constant occurrence in human lives. Its devastating effect can be globally observed in innumerable forms. The cost in sorrow and pain, anguish and distress is inestimable. As a matter of fact, a great proportion of it is virtually invisible. Certainly, satellite technology reveals some forms of violence such as civil unrest and terrorism, detectable to television viewers on a frequent basis. A great proportion of violence however occurs out of sight in offices, homes or even in the health and social institutions established to care for the general public. Child-to-parent violence (CPV) is an issue that is gradually gaining prominence. In the discussion about domestic violence, large portions of literatures address issues such as spousal mistreatment, spousal abuse and so on. In most scenarios, the perpetrator of domestic violence is either one of the adults in the family. Now, cases are being reported all 
over the world in which children are no longer the victims, but the aggressors. They are no longer timid, but malicious. Cottrell (2001) regarded CPV to be actions intentionally carried out by children to obtain control over parents, elicit monetary, psychological or physical harm. Literatures on CPV are somewhat restricted. This is largely due to the sacredness accorded to privacy in a family. However, researches have been carried out specifically on the issue nonetheless.

An issue of debate is the distinction between CPV and typical adolescent behaviour. Pereira (2006) clarified this by defining CPV to be recurrent fits of violence, which could be verbal (bullying, insults, shaming), physical (flinging of objects, shoving, striking, assault), and non-verbal (demolition of cherished possessions, threatening gestures) against parents or guardians. Distinction can as well be obtained from power dynamics. Child-to-parent-abuse entails the blatant disregard for authority from the part of the child, involving repeated attempts to control, strong-arm and dictate over other members of the family. This is largely distinguishable from behaviours that can be labelled to be associated with a child's developmental stages. According to Gallagher (2008), the worldwide prevalence of CPV is pegged at 18 percent. Victims of CPV often keep mute due to a desire to keep the family image intact, fear of embarrassment and fear of the child's reaction (Perez and Pereira, 2006).

According to Cottrell and Monk (2004), CPV is more likely to occur in low income families. It was however argued by Calvete, Orue and Sampedro (2011) that it can be found in all families, being it low income, middle income or high income. Experts in clinical practices have stated that CPV is on the rise. The situation is getting so acute that parents/guardians feel weak. The power dynamics have been overturned and they are more or less at the mercy of the children, having lost the capacity to assert authority (Omer, 2011).

$\mathrm{CPV}$ can have severe consequences for the child, parents, and other members of the society as indicated by Cottrell and Monk (2004), Nock and Kazdin (2002). On the part of the child, a constant abuse of parents/guardians indicates reduced frustration tolerance, increased hostile behaviours and more arduous personalities in comparison to the general populace, inclusive of parents and other children. According to Walsh and Krienert (2007), this culminates into attacks on parents. Attacks on parents may break the filial bond, creating distance between parents/guardian and the child within a short time. Children will no longer be able to learn from parents/guardians. The latter might be too scared to make an attempt. All they would want is for the pain to end. People need bonds to survive in the society and the parental bond is the most significant of all. When the ties with the parents are cut off, the effectiveness of the family institution comes into question. The children could become prone to bouts of tantrums and rages, which taints their personality in the outside world. Pagani et al. (2004) cited destructive behaviours at school being a precursor to CPV. According to Agnew and Huguley (1989), Kratcoski and Kratcoski (1982), CPV could result in the children hanging out with other violent juveniles. CPV could result in the child feeling insecure, distrustful, and hypersensitive. A constant occurrence of CPV could lead to mental health problems (Kennedy et al., 2010).

Then, the parents would be in a constant state of terror. Asides from this, they could be physically injured and psychologically unhinged. A psychologically unhinged parent cannot properly raise a child. CPV could even result into parents/guardians being afraid of their own children/wards. This was documented in the work of Gallagher (2004) in which the case of a mother, named Anna was cited. Anna was physically, verbally and psychologically traumatized by her son. A physically injured parent will remain scared and scarred, never forgetting the abuse, always lingering in his/her mind. Sleepless nights could set in and restless days could become the norm. Generally, physical abuse suffered by the parents could be assault, hazing, battered person syndrome (a scenario in which the victims murder the aggressor), sleep deprivation, sleep distortion, withdrawal of food, recurrent slapping, withholding medical care for injuries, etc. Psychological abuse suffered by parents/guardians includes insults, tantrums, 
gas-lighting, and so on. Possible consequences of abuse on parents also include chronic depression, anxiety, acute physical injuries and even death.

Possible effects on the society could be a sizeable reduction in labour force resulting from the death of parents which is likely with the frequent occurrence of CPV. In addition there is a significant possibility to be an increase in deviant acts (Agnew and Huguley, 1989) as children are not raised in line with established values in the society, as the parents/guardians are too scared to impose authority on the children/wards (Gallagher, 2004). Furthermore, unborn babies could even be caught in the crossfire. This can be seen in a situation where a teenager physically abuses his/her pregnant biological/foster mum or guardian. It could become so acute that she suffers a miscarriage. Then, other children are at risk of being influenced by witnessing cases of CPV. In line with these, it becomes relevant to ascertain the causes of CPV.

In a bid to establish the causes of CPV, the study seeks to determine the association between the offender's religion and engagement in financial CPV. Also, there is an interest in the association between offender's age and involvement in psychological violence. Finally, there is an interest in the association between offender's gender and engagement in physical CPV. The literatures addressing $\mathrm{CPV}$ in Nigeria are deficient. This study will provide greater comprehension of CPV in general and CPV in Nigeria specifically.

In the view of Aroca-Montolío, Lorenzo-Moledo and Miró-Pérez (2014), CPV has three forms:

1. Physical: This consists of acts aimed at the parents/guardians, including shoving, spitting, punching, making threats with harmful objects, attacking with harmful objects, destroying or threatening to destroy the family house.

2. Psychological: This could be emotional, verbal or non-verbal. Engaging in CPV of this sort entails intimidation, insults, spiteful teasing, demanding unreasonable acts or items, lying, running away from home, making threats to commit suicide.

3. Financial or Economic: This involves theft of funds, prized possessions, incurring unreasonable debts to be paid by guardians/parents or blackmailing guardians/parents to pay for what is beyond their economic power.

According to Bailín, Tobeña and Sarasa (2007), scenarios of CPV start with some form of economic violence, and then moves to psychological violence and finally reaching physical violence, attaining a level in which all three forms are at play. Spitzberg and Cupach (2011) conceptualized a model of interaction resulting to CPV. Consult figure 1 for a pictorial representation of the model in conjunction with the forms of CPV stated by Aroca-Montolío, Lorenzo-Moledo and Miró-Pérez (2014). The stages are as follows:

1. A request is made by the child

2. Illuminating information is asked for by the parent.

3. The child politely responds, providing the information requested for.

4. The parent recognizes the child's viewpoint but chooses to say "no" centered on the provided information, while probably continuing the discussion regarding a likely "next time".

5. The child attempts to alter the parent's mind by requesting the parent to clarify the decision, at times making use of the information to persistently test the parent until convinced that the answer would not be altered.

6. If the parent stands firm to his or her resolution, the child may start using insulting comments and threats, pester the parent by stalking the parent, and finally retorting with verbal intimidations, emotional abuse, physical force, and often demolition of property or monetary ruin.

The model in Figure 1 represents a diagrammatic representation of the stages involved in the exhibition of CPV as given by Spitzberg and Cupach (2011) combined with the forms of CPV stated by Aroca-Montolío, Lorenzo-Moledo and Miró-Pérez (2014). 
Figure 1. A model depicting the relationship between Sociodemographic Factors and Engagement in CPV

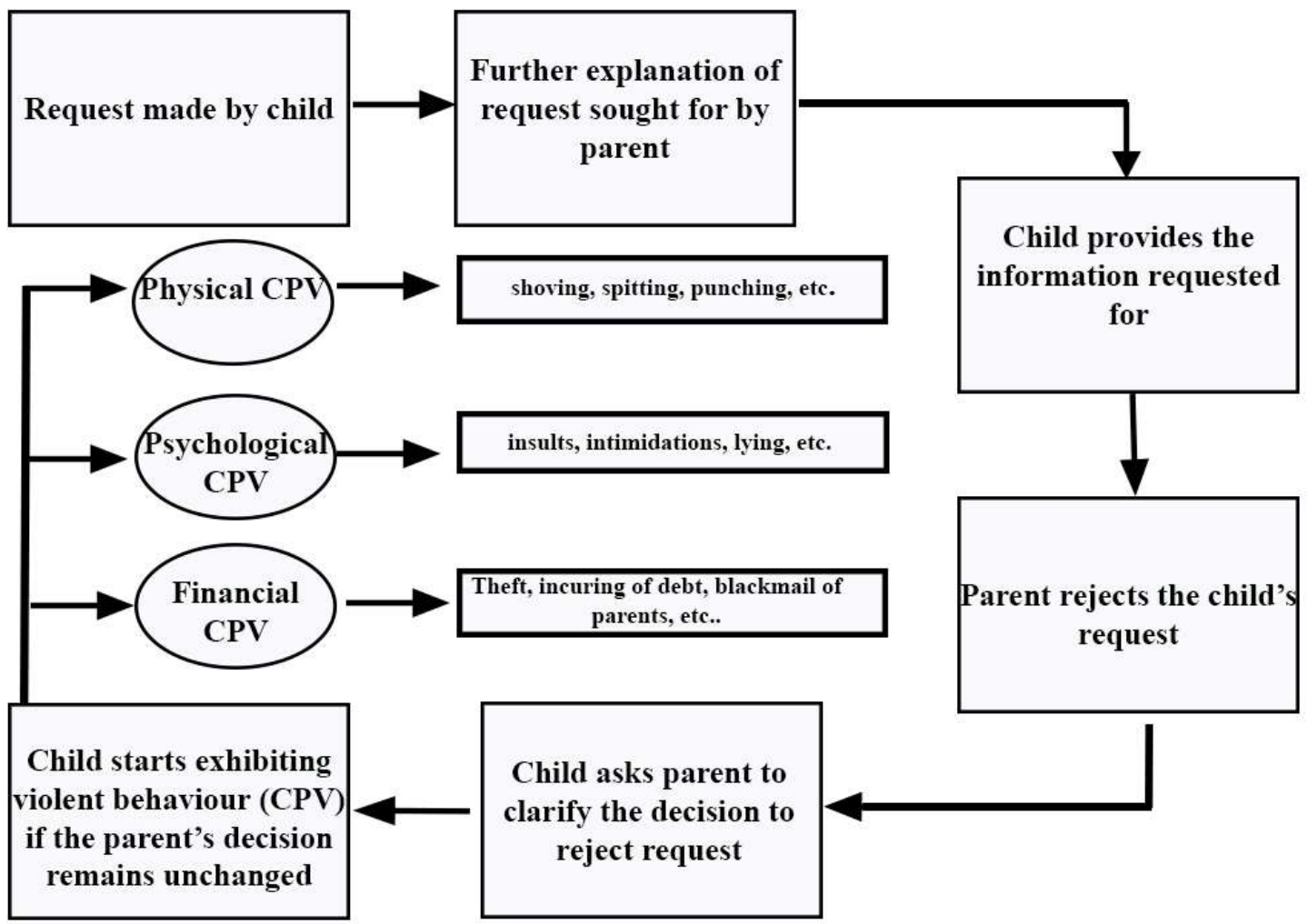

Source: Researchers' conception, constructed from the works of Spitzberg and Cupach (2011), Aroca-Montolío, Lorenzo-Moledo and Miró-Pérez (2014).

Furthermore, studies have sought to determine the profiles of abusive children, such as those conducted by Routt and Anderson (2011), Edenborough et al. (2008) and Gallagher (2009). These studies revealed male teenage offenders to be between 60 percent and 80 percent of the total offenders. A study carried out by Ibabe and Jaureguizar (2011) revealed that male adolescents dominate the sphere of physical violence and the female adolescents dominating psychological violence. As respect to age, studies by Walsh and Krienert (2007) and Sánchez (2008) pegged the age of offenders to be in the range of 14 to 17. A review carried out by Perez and Pereira (2006) shows that a child leaning towards CPV will start showing signs of violence around the age of eleven.

Studies have as well sought to peg the profile of the parents/guardians who are victims of CPV. According to Romero et al (2005) and Walsh and Krienert (2007), female guardians/parents or other members of the family are usually the assaulted. This, according to Cottrell and Monk (2004) is because females are assumed to be weak by the aggressors. Gallagher (2004) stated that this is because females spend more time in the parenting role than males. As to the age of victims, Edenborough et al. (2008) stated the most common age bracket of victims to be between $40-50$ years.

Different researches have also been carried out to determine the rate at which CPV occurs. Browne and Hamilton (1998) in a study of UK undergraduate students revealed that 14\% 
of students had behaved violently to parents. Van Langenhove (2004) revealed in a research carried out among Belgian school students that $14.8 \%$ of students abused their parents in some way with a great proportion of being emotional in nature with $3.9 \%$ of the students ceding to physically abusing their parents. Wakabayas (1982) in Japan estimated that 3.4\% of youth were violent to parents. Helin, Chevalier and Born (2004) carried out a study among Belgian youths in a domestic training centre, revealing that $22 \%$ exhibited violent behaviours toward their mothers. According to Birnbauer (2005), a local newspaper article on CPV in Sydney reported a prevalence figure of $70 \%$. This was based on incidents of intimidation, physical, psychological abuse, financial and verbal torment. According to Rand (1997), out of 213,000 emergency department calls documented regarding domestic violence 1994, 5.4\% had the culprit branded as a child of the casualty.

Consistent behaviour is determined by the related fruitfulness (rewards or absence of punishment). This is the basic premise of social learning theory, as is found in the work of Akers (1998). In essence, social behaviour is attained by imitating others or through direct conditioning. Behaviour is more likely to be repeated if found to be rewarding (positive reinforcement) or there is a removal of punishment (negative reinforcement). Therefore, the history of rewards/punishments determines the consistency of an action. Adolescents study the reaction of the parents/guardians to CPV with their reaction (positive or negative) determining if the abuse continues. For instance, an adolescent could continually pester his/her parents to purchase an expensive item that is beyond their spending power (an example of financial CPV). If the parents/guardians cave in and gratify the desire, it serves as a positive reinforcement, making it more plausible for the adolescent to repeat such an act. A negative reinforcement entails the parents/guardians putting an end to reservations they might have had concerning the adolescent's demands.

Furthermore, a juvenile offender could shove parents/guardians in order to stop them from interfering in his/her actions. If the parents/ guardians back down, the offender learns to repeat such an action in the future and could even make threats. A scenario as such involves physical and psychological violence. According to Rada (2014a, 2018), parents are the most vital spring of support for children. Even the parents often end up depending on their grown-up children for support. In essence, parent-child relation is a natural part of life. The family is meant to be a safe space. It ought to be an abode wherein members find support in one another. It ought to be filled with love and affection. A situation where violence is experienced is so unnatural. Violence impedes the love, support and care that ought to be found in a family. It replaces it with fear, hate and uncertainty.

Another aspect in social learning theory is imitation. Karami (2007) conceived imitation to be the repetition of an action by man after perception. The youth, middle age and even the elderly people are all engaged in imitation. Abbas (2008) defined imitation to be a behaviour grounded on a pattern.

According to Mehdi, Nariman and Alireza (2014), the following are the stages involved in imitation:

1. Unknown imitation, commencing at birth till age two.

2. Imitation in a precise meaning, starting at age two till age seven. This is more or less same as unknown imitation.

3. Known imitation, commencing after age seven. This is the apex form of imitation

Following these stages as found in the work of Mehdi, Nariman and Alireza (2014), a child can consciously imitate actions of his/her friend whose parents/guardians got an expensive item for after consistent tantrums. The aggressors in CPV are above the age of seven as that is where the stage of known imitation commences. The theory becomes relevant to the study as many aggressors imitate their deviant friends or peers and in turning to become deviants themselves. An issue worthy of note is the concept of intergenerational transmission of violence. 
When an offender learns violent conduct by observing parents/guardians, intergenerational transmission of violence is said to have taken place. Rada (2014b) "found in the correlation between violence in the family of origin and that in the family of procreation, the greatest manifestation of violence in the family of procreation was reported by subjects who were both witnesses and victims of violence in the family of origin." Empirical backing for social learning theory is delivered by statistics indicating that a large fraction of children who commit CPV have been abused by their parents, or observed domestic violence (Boxer, Gullan and Mahoney, 2009; Kennair and Mellor 2007). Explicitly, sons may pick up the role of perpetrators when abused by their fathers or when they see their fathers injuring their mothers. In divergence, daughters may pick up the victim role from observing their mothers in that position. Corresponding with this theory, Boxer, Gullan and Mahoney, (2009) corroborated empirically that sons were more likely to demonstrate aggressiveness against their mothers if the mother was abused by the father.

\section{Material and methods}

In 2018, the study was carried out in Ilorin metropolis of Kwara State, Nigeria. Ilorin is divided into three local governments; Ilorin South, Ilorin West and Ilorin East. Ilorin can be found roughly 291 kilometres north of Lagos and roughly 488.7 kilometres west of Abuja (Nigeria's capital city). When the 2006 population census was conducted, it was established that 777,667 people are in Ilorin.

The multistage sampling technique was used to select 270 respondents. This commenced with the use of cluster sampling to partition the study area into three; Ilorin south, Ilorin west and Ilorin east. Ilorin south has 11 wards, Ilorin west has 12 wards and Ilorin east has 12 wards. Following this, the simple random sampling technique was used to select three wards from each local government areas, making a total of nine selected wards. Finally, the purposive sampling technique was used to select 30 respondents from each selected ward. This makes a total of 270 respondents. The purposive sampling technique was used because of the need to select respondents who have a direct association with CPV offenders and have witnessed the act in person, such as parents, brothers, close friends, teachers, etc. Written informed consent was acquired from all respondents of the study. The respondents were informed that withdrawal from the study at any time was possible. Furthermore, utmost confidentiality was guaranteed to the respondents. The study was approved by the Ethical Review Committee of University of Ilorin (UERC/ASN/2017/945).The presented results are based on the 258 copies of questionnaire retrieved from the field and found to be valid. Chi square was used to test the hypotheses of study.

\section{Results}

Table 1 shows the basic structure of the analyzed sample.

Table 1. Structure of respondents

\begin{tabular}{|l|c|}
\hline Socio-demographic factors & Percentage (\%) \\
\hline Age & 2 \\
\hline 18 and below & 25 \\
\hline $19-29$ & 33 \\
\hline $30-40$ & 32 \\
\hline $41-51$ & 8 \\
\hline 52 and above & \\
\hline & \\
\hline
\end{tabular}




\begin{tabular}{|l|c|}
\hline Socio-demographic factors & Percentage (\%) \\
\hline Gender & \\
\hline Male & 57 \\
\hline Female & 43 \\
\hline Educational Level & 9 \\
\hline No formal education & 18 \\
\hline Primary & \\
\hline & \\
\hline Employment category & 29 \\
\hline Public/civil employment & 23 \\
\hline Private employment & 31 \\
\hline Self-employment & 17 \\
\hline Unemployed & \\
\hline & \\
\hline Ethnic Group & 48 \\
\hline Yoruba & 25 \\
\hline Hausa & 15 \\
\hline Ibo & 12 \\
\hline Others & \\
\hline \multicolumn{1}{|c|}{ Source: Researchers' Fieldwork (2018) } \\
\hline Income Category & 37 \\
\hline Low income & 53 \\
\hline Middle income & 10 \\
\hline High income & \\
\hline & \\
\hline Total & \\
\hline & \\
\hline & \\
\hline & \\
\hline & \\
\hline & \\
\hline
\end{tabular}

\section{Test of Hypotheses}

\section{Hypothesis One}

Ho: CPV offender's religion is not related to engagement in financial violence. H1: CPV offender's religion is related to engagement in financial violence.

Table 2. Perception of Engagement in Financial Violence on the Basis of Religion

\begin{tabular}{|c|c|c|c|}
\hline \multirow[t]{2}{*}{ Offender's Religion } & \multicolumn{2}{|c|}{ Engagement in Financial Violence } & \multirow{2}{*}{$\begin{array}{l}\text { Total } \\
\text { N }(\%)\end{array}$} \\
\hline & $\begin{array}{c}\text { Yes } \\
\text { N (\%) }\end{array}$ & $\begin{array}{c}\text { No } \\
N(\%)\end{array}$ & \\
\hline Islam & $70(54)$ & $60(46)$ & $130(100)$ \\
\hline Christianity & $75(59)$ & $53(41)$ & $128(100)$ \\
\hline
\end{tabular}

Source: Researchers' Fieldwork $(2018) \mathrm{C}^{2}(1, \mathrm{~N}=258)=0.59, \mathrm{p}=.44$

According to religion, $59 \%$ of Christian offenders engage in financial violence compared with $54 \%$ of Muslim offenders. The calculated value of the chi square stands at 0.59 . The degree of freedom is 1 and the level of significance is 0.44 . Based on this, no significant association was found between CPV offender's religion and engagement in financial violence. 


\section{Hypothesis Two}

Ho: CPV offender's age is not related to engagement in psychological violence.

H1: CPV offender's age is related to engagement in psychological violence.

Table 3.Perception of Engagement in Psychological Violence on the Basis of Age

\begin{tabular}{|c|c|c|c|}
\hline \multirow{2}{*}{ Offender's Age } & \multicolumn{2}{|c|}{ Engagement in Psychological Violence } & Total \\
\cline { 2 - 4 } & $\begin{array}{c}\text { Yes } \\
\text { N }(\%)\end{array}$ & $\begin{array}{c}\text { No } \\
\text { N }(\%)\end{array}$ & \\
\hline 14 and Below & $56(43)$ & $75(57)$ & $131(100)$ \\
\hline $15-17$ & $88(69)$ & $39(31)$ & $127(100)$ \\
\hline
\end{tabular}

According to age, $43 \%$ of offenders aged 14 and below engage in psychological violence compared with $69 \%$ of offenders aged $15-17$.The calculated value of the chi square stands at 18.4. The degree of freedom is 1 and the level of significance is 0.001 . Based on this, a significant association exists between CPV offender's age and engagement in psychological violence.

\section{Hypothesis Three}

Ho: Males are not likely to engage in physical CPV.

H1: Males are likely to engage in physical CPV.

Table 4. Perception of Engagement in Physical Aggression on the basis of Gender

\begin{tabular}{|c|c|c|c|}
\hline \multirow{2}{*}{ Offender's Gender } & \multicolumn{2}{|c|}{ Engagement in Physical Aggression } & \multirow{2}{*}{ Total } \\
\cline { 2 - 3 } & Yes & No & N $(\%)$ \\
\hline Male & N $(\%)$ & $48(39)$ & $122(100)$ \\
\hline Female & $74(61)$ & $101(74)$ & $136(100)$ \\
\hline
\end{tabular}

Source: Researchers' Fieldwork $(2018) \mathrm{C}^{2}(1, \mathrm{~N}=258)=32.1, \mathrm{p}=.001$

According to gender, more men than women engage in physical aggression $(61 \%$ versus $26 \%)$. The calculated value of the chi square stands at 32.1 . The degree of freedom is 1 and the level of significance is 0.001 . Based on this, a significant association exists between CPV offender's gender and engagement in physical violence.

\section{Discussions}

The result of hypothesis one indicates the absence of a significant association between the CPV offender's religion and engagement in financial violence in Ilorin metropolis. This shows that religion is not a significant factor influencing CPV offenders. This builds on the findings of Rada, Turcu and Bucinschi (2011) who established that perpetrators of domestic violence are orthodox Christians though the rate of church attendance is low. In essence, CPV is knows no boundary in terms of religion. It occurs among both Christian and Muslim families in Ilorin metropolis. A study carried out by Boxer, Gullan and Mahoney, (2009) established that CPV occurs largely in families riddled with domestic violence. This could be between the spouses or between the parent(s) and the child. Boxer, Gullan and Mahoney, (2009) further stated that CPV was likely to occur frequently between the opposite sexes i.e. a male child is 
aggressive towards the mother and a female child is aggressive towards the father. In support of Boxer, Gullan and Mahoney, (2009), Cottrell and Monk (2004) established that children who abuse their parents have themselves been abused at a tender age. When the adolescents grow older, the aggression experienced is then directed towards the abusive parent(s).

Hypothesis two reveals a significant association between age and engagement in psychological violence. In line with this, the results show that children between the age range of 15-17 are more likely to engage in psychological violence against parents. Psychological CPV entails threats, insults, intimidation addressed against parents by children. This is somewhat in line with the findings of Pagani et al. (2009) that children between 14-17 years are the most likely to be involved in CPV in USA and UK. Perez and Pereira (2006) also discovered the peak age of violence to be in the range of 15-17 years. The present study found what is similar to the work of Figueira-McDonough (1985), in which a study was carried out among 15-year-olds, revealing that they exhibited violent behaviour towards their parents. A study by Evans and Warren-Sohlberg (1989) presented a different result, revealing that 11 percent of CPV offenders were under 10 years old. Other findings different from the revelations of this study include those by González-Álvarez (2012) and Cottrell and Monk (2004) who have traced CPV to the presence of a low compassion in children. In the view of Ibabe and Jaureguizar (2011), the significant factor causing CPV is the psychopathological disorders in adolescents who attack their guardians/parents. Cottrell and Monk (2004) further established such factors as attachment disorders, conduct disorder, intermittent explosive disorder, antisocial personality disorder, anxiety disorder, etc. to be factors influencing engagement in CPV.

The result from hypothesis three indicates that males are more likely to engage in physical CPV. Aroca-Montolío, Lorenzo-Moledo and Miró-Pérez (2014) established physical CPV to include slapping, shoving, destruction of parents' property, punching, etc. The present study found what is similar to the researches undertaken by Walsh and Krienert (2009), Pagani et al. (2009), Condry and Miles (2014), Humphreys and Mullender (2002) and Gallagher (2008). Walsh and Krienert (2009) established that out of 100,000 CPV offenders, 63 percent of them were male with 37 percent being female. In addition, Pagani et al. (2009) established that males engage in CPV more than females. This was based on a study of physical and verbal aggression towards fathers. Condry and Miles (2014) also discovered that male adolescents are more aggressive towards parents than female counterpart. Humphreys and Mullender (2002) revealed what is similar to this study when the findings indicate a boy hitting his mother. In an analysis of 3,600 participants, Gallagher (2008) revealed that male perpetrators of CPV were $72 \%$. As a contrast to the findings of this study, numerous researches, such as those by Agnew and Huguley (1989), World Health Organization (2002) have made known that gender does not play a significant in the total number of CPV perpetrators; though, males have been indicated to be more likely to impose physical violence with females more likely to impose psychological violence. The present study found what is different compared to the works of Cottrell (2001) and Bobic (2004). Their research traced the causes of CPV to factors that "transcend" sociodemographic factors such as age, gender and religion. In their studies, the stated causes of CPV are arguments, aggressive behavioural tendencies, uncontrolled feelings, frustration, gang culture, fear, drugs and alcohol, lack of respect for parents, mental illness, witnessing abuses at home, absence of adequate role models, and corporal punishment.

The model in Figure 2 represents the nature of relationship between the three sociodemographic factors explored in relation to the three types of CPV stated in the study. 
Figure 2. A model depicting the relationship between Socio-demographic Factors and Engagement in CPV

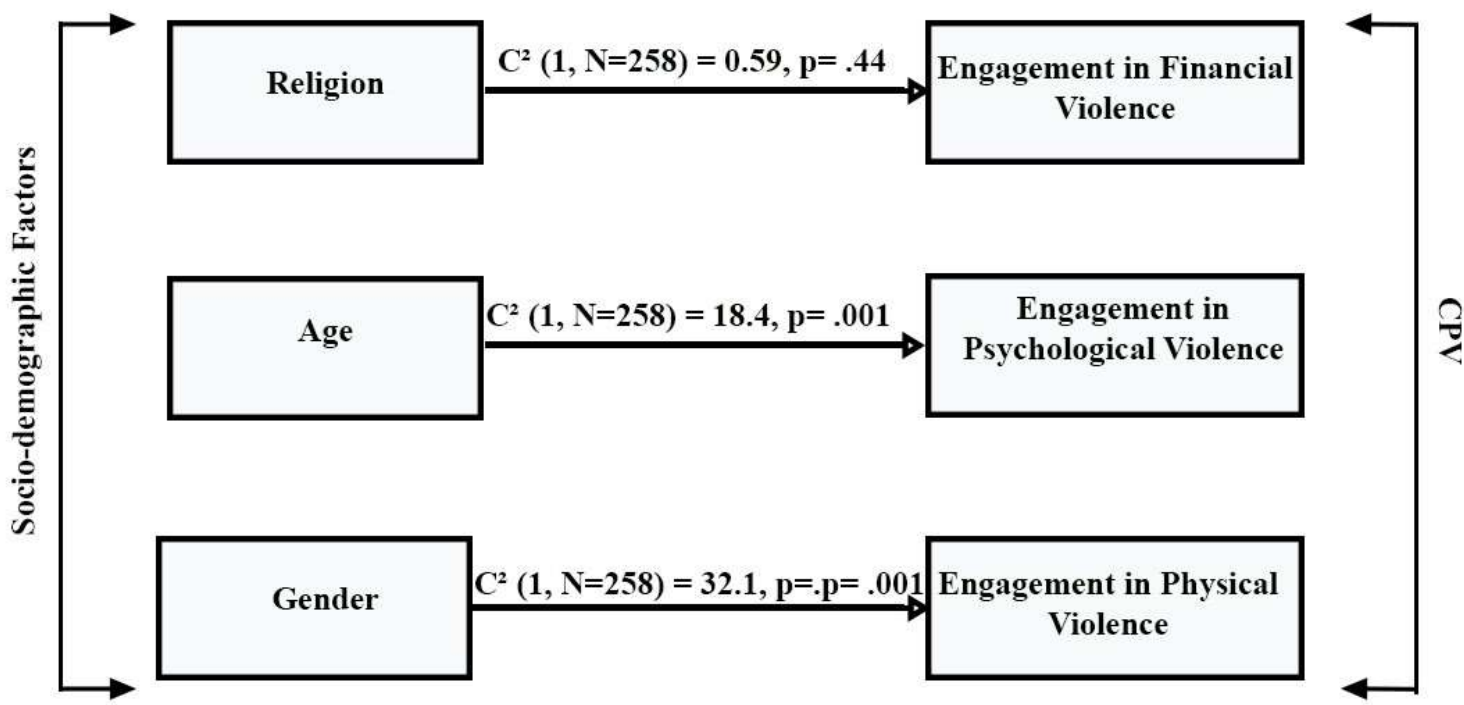

Source: Researchers' conception, adapted from fieldwork (2018)

\section{Conclusions}

CPV has adverse effects on the parents. They are affected physically, mentally and financially. Physically, they are injured by their children. They bear scars of abuse, which can be psychologically unnerving. The parents become scared of their children. Financially, children extort their parents of funds that could have been used to foster their growth and well-being. The parents could have to settle debts with funds that could have been used to foster the child's development, the family's well-being, and so on.

Based on the findings, the study recommends that non-governmental organizations could be established to educate the public on CPV. There is a dearth of available literatures on CPV in Africa. This could largely be a consequence of the continent's culture. An event such as CPV is seen to be shameful and to be settled within the family. Also, the government could establish juvenile rehabilitation facilities to socialize the CPV offenders on the acceptable behaviours in the society and how they ought to relate with their parents. Then, further researches should be carried out on the issue of CPV in African societies as the available literatures severely are lacking.

\section{Bibliography}

1. Abbas, M.M., 2008. Role of patterns in education. Tehran: Peivand Publication.

2. Agnew, R. and Huguley, S., 1989. Adolescent violence towards parents. Journal of Marriage and Family. 51(3), pp. 699-771.

3. Akers, R.L., 1998. Social Learning and Social Structure: A General Theory of Crime and Deviance. Boston, MA: Northeastern University Press.

4. Aroca-Montolío, C., Lorenzo-Moledo, M. and Miró-Pérez, C., 2014. La violencia filioparental: un análisis de sus claves [Child-parent violence: an analysis of the key points]. Anales de psicología, 30(1), pp. 157-170. 
5. Bailín, C., Tobeña, R. and Sarasa, R., 2007. Menores que agreden a sus padres: resultados de la revision bibliográfica [Children who assault their parents: the results of the literature review]. Revista de Psicología General y Aplicada, 60(1-2), pp. 135-148.

6. Birnbauer, W., 2005. 70\% of mums face violence from teenagers. Sunday Age, May 22nd.

7. Bobic, N., 2004. Adolescent Violence towards Parents. Australian Domestic \& Family violence Clearing House, pp. 1-14.

8. Boxer, P., Gullan, R.L., and Mahoney, A., 2009. Adolescents' physical aggression towards their parents in a clinical-referred sample. Journal of Clinical Child and Adolescent Psychology, 38, pp. 106-116.

9. Browne, K.D. and Hamilton, C.E., 1998. Physical violence between young adults and their parents: Associations with a history of child maltreatment. Journal of Family Violence, 13(1), pp. 59-79.

10. Calvete, E., Orue, I. and Sampedro, R., 2011. Violencia filio-parental en la adolescencia: características ambientales y personales [Filio-parental violence in adolescence: environmental and personal characteristics]. Infancia y Aprendizaje, 34, pp. 349-363.

11. Condry, R. and Miles, C., 2014. Adolescent to Parent Violence: Framing and mapping a hidden problem. Criminology and Criminal Justice, 14(3), pp. 257-275.

12. Cottrell, B., 2001. Parent abuse: the abuse of parents by their teenage children. Ottawa: Health Issues Division.

13. Cottrell, B. and Monk, P., 2004. Adolescent-to-parent abuse: A qualitative overview of common themes. Journal of Family Issues, 25(8), pp. 1072-1095.

14. Edenborough, M., Jackson, D., Mannix, J. and Wilkes, L., 2008. Living in the red zone: the experience of childto-mother violence. Child and Family Social Work, 13 (4), pp. 464-473.

15. Evans, D. and Warren-Sohlberg, L., 1989. A pattern analysis of adolescent abusive behaviour towards parents. Journal of Adolescent Research, 3(2), pp. 210-216.

16. Figueira-McDonough, J., 1985. Are girls different? Gender discrepancies between delinquent behaviour and control. Child Welfare, 64, pp. 273-289.

17. Gallagher, E., 2004. Youth who victimise their parents. Australian and New Zealand Journal of Family Therapy, 25(2), pp. 94-105.

18. Gallagher, E., 2008. Children's violence to parents: a critical literature review. Melbourne: Monash University.

19. Gallagher, E., 2009. Children's violence to parents. Research Seminary. [online] Available at: http://www.noviolence.com.au/public/seminarpape rs/gallagherslides.pdf. [Accessed 10 November 2018].

20. González-Álvarez, M., 2012. Violencia intrafamiliar: características descriptivas, factores de riesgo y propuesta de un plan de intervención [Domestic violence: descriptive characteristics, risk factors and a proposed plan of intervention]. Madrid: Universidad Complutense de Madrid.

21. Helin, D., Chevalier, V. and Born, M., 2004. Ces adolescents qui agresent leur mére. Neuropsychiatrie de l'Enfanceet de l'Adolescence, 52(1), pp. 24-29.

22. Humphreys, C. and Mullender, A., 2002. Children and Domestic Violence: A Research Overview of the Impact on Children. Totnes: Research in Practice.

23. Ibabe, I. and Jaureguizar, J., 2011. Hasta qué punto la violencia filio-parental es bidireccional? [To what extent is child-parent violence bidirectional?] Anales de psicología, $27(2)$, pp. 265-277.

24. Karami, N.R., 2007. Educational psychology. Tehran: Roshd Publication.

25. Kennair, N. and Mellor, D., 2007. Parent abuse: a review. Child Psychiatry and Human Development, 38(3), pp. 203-219. 
26. Kennedy, T.D., Edmonds, W.A., Dann, K.T.J. and Burnett, K.F., 2010. The clinical and adaptive features of young offenders of child-parent violence. Journal of Family Violence, 25(5), pp. 509-520.

27. Kratcoski, P.C. and Kratcoski, L.D., 1982. The relationship of victimization through child abuse to aggressive delinquent behaviour. Victimology: An International Journal, 7(1-4), pp. 199-203.

28. Mehdi, R.M., Nariman, F. and Alireza, M., 2014. The Gabriel Tard's theory of imitation and enforcement of imprisonment punishment. World Scientific News, 6, pp. 17-25.

29. Nock, M.K. and Kazdin, A.E., 2002. Parent-directed physical aggression by clinic-referred youths. Journal of Clinical Child and Adolescent Psychology, 31(2), pp. 193-205.

30. Omer, H., 2004. Nonviolent resistance: A new approach to violent and self-destructive children. Cambridge: Cambridge University Press.

31. Pagani, L.S., Tremblay, R.E., Nagin, D., Zoccolillo, M., Vitaro, M. and McDuff, P., 2004. Risk factor models for adolescent verbal and physical aggression toward mothers. International Journal of Behavioral Development, 28(6), pp. 528-537.

32. Pagani, L., Tremblay, R.E., Nagin, D., Zoccolillo, V.F., and McDuff, P., 2009. Risk factors for adolescent verbal and physical aggression toward fathers. Journal of Family Violence, 24, pp. 173-182.

33. Pereira, R., 2006. Violencia filio-parental: un fenómeno emergente [Child-parent violence: an emerging phenomenon]. Revista Mosaico, 36, pp. 27-32.

34. Perez, T. and Pereira, R., 2006. Violencia filio-parental: revisión de la bibliografía [Childparent violence: a literature review]. Revista Mosaico, 36, pp. 1-13.

35. Rada, C., Turcu, S. and Bucinschi, C., 2011. Domestic violence in Romania: The relationship between social determinants of health and abuse. Entre Nous, The European Magazine for Sexual and Reproductive Health, 73, pp. 22-24.

36. Rada, C., 2014a. Intergenerational family support in Romania, Rev. Psih., 60(4), pp. $293-$ 303.

37. Rada, C., 2014b. Violence against women by male partners and against children within the family: prevalence, associated factors, and intergenerational transmission in Romania: a cross-sectional study. BMC Public Health, [e-journal] 14(129). https://doi.org/10.1186/1471-2458-14-129.

38. Rada, C., 2018. Aging and intergenerational care, Anthropological Researches and Studies, [e-journal] 8, pp.134-143, http://doi.org/10.26758/8.1.13.

39. Rand, M.R., 1997. Violence-related injuries treated in hospital emergency departments. Washington, U.S.: Department of Justice.

40. Romero, F., Melero, A., Cánovas, C. and Antolín, M., 2005. La violencia de los jóvenes en la familia: una aproximación a los menores denunciados por sus padres [Youth violence in the family: a study of juveniles reported to police by their parents]. Barcelona: Àmbit social i criminològic. Investigació Centre d'Estudis Jurídics i Formació especialitzada. Generalitat de Catalunya, Departament de Justicia [Social and criminological area. Research Centre for Legal Studies and Specialist Training Programme. Government of Catalonia, Department of Justice].

41. Routt, G. and Anderson, L., 2011. Adolescent violence towards parents. Journal of Aggression Maltreatment \& Trauma, 20(1), pp. 1-18.

42. Sánchez, J., 2008. Análisis y puesta en marcha en uncentro de menores de un programa de intervención con menores y familias que maltratan a sus padres [Analysis and implementation in a youth centre of a program of intervention with children and families who abuse their parents]. Valencia: Universidad de Valencia. 
43. Spitzberg, B.H. and Cupach, W.R., 2011. Adolescent-to-Parent Abuse: Exploring the Communicative Patterns Leading to Verbal, Physical, and Emotional Abuse. The Dark Side of Interpersonal Communication (2nd ed.). New York: Routledge.

44. Van Langenhove, K., 2004. Intrafamiliaal geweld bijjongeren: onderzoek naarvoorkomen en kenmerken van oudermishandelingbij TSO- en BSO- leerlingen. Brussels, Belgium: Brussels Free University.

45. Wakabayas, H.S., 1982. Family violence in Japan: a compilation of data from the department of psychiatry, Nagoya University Hospital. Japanese J. Psychiatric Neuroogyl, 42, pp. 5-10.

46. Walsh, J.A. and Krienert, J.L., 2007. Child-parent violence: an empirical analysis of offender, victim, and event characteristics in a national sample of reported incidents. Journal of Family Violence, 22, pp. 563-574.

47. Walsh, J.A. and Krienert, J.L., 2009. A decade of child-initiated family violence: Comparative analysis of child-parent violence and parricide examining offender, victim and event characteristics in a national sample of reported incidents, 1995-2005. Journal of Interpersonal Violence, 24, pp. 1450-1477.

48. ***World Health Organization. 2002. World report on violence and health. Geneva: World Health Organization. 